\title{
Research at Two Small Canadian Universities: The Views of Faculty
}

\section{DAVID FURROW}

Mount Saint Vincent University

\section{COLIN TAYLOR}

Trent University

\begin{abstract}
Faculty members at two small Canadian universities were sent a questionnaire in which they were asked about research activities and preferences, views of themselves as researchers, and views about factors which they felt either constrained or facilitated research activities. Respondents were highly committed to research, though gave teaching an equally high priority. Views of influences were similar across universities, with non-teaching commitments, teaching commitments, availability of graduate students, and availability of library holdings seen as most detrimental. Personal motivation and university research offices were seen as positive influences. We consider how faculty views might affect university policy and suggest, among other things, that universities might want to develop a formal policy in which individual faculty be allowed to specialize to some extent in research or teaching.

This research was supported by the Research Offices at Mount Saint Vincent and Trent Universities, of which the authors were the Director and Associate Dean, respectively. Thanks to all faculty members who took the time to respond to our questionnaire, and especially to Renee Dankner and Joe Muldoon for their assistance.
\end{abstract}




\section{Résumé}

Les professeurs des deux petites universités canadiennes ont répondu à un questionnaire portant sur leurs activités et préférences de recherche, leurs représentations d'eux-mêmes comme chercheurs et leurs perceptions des facteurs qui aident ou gênent les activités de recherches. Les professeurs accordent une grande priorité à la recherche ainsi qu'à l'enseignement. Peu de différences sont observées dans les perceptions des professeurs des deux universités. Les plus grands obstacles sont les fonctions de participation à l'université, les charges d'enseignement, la disponibilité des étudiants des deuxième et troisième cycles et la disponibilité des livres à la bibliothèque. La motivation des chercheurs et les bureaux de l'administration de la recherche sont perçus de manière positive. Les auteurs traitent par la suite de la façon dont les représentations des professeurs peuvent affecter les politique universitaires. Ils suggèrent, par exemple, que les universités puissent autoriser les professeurs à consacrer plus de temps à la recherche ou à l'enseignement.

Factors affecting research and research funding in small Canadian Universities have received particular attention over the past decade (Bélanger, 1989; Ingalls, 1982; Owen, 1992; Perkin, 1985). There are several reasons for an especial focus here. One has been the sense among many commentators that the research climate at small institutions is constrained (Owen, 1992). Further, there is the enduring fact that small universities receive a disproportionately small number of federal research council grants. Faculty members at small universities who apply to the Natural Sciences and Engineering Council (NSERC) or the Social Sciences and Humanities Research Council (SSHRC) enjoy a lower success rate than their colleagues at larger universities, and smaller proportions of them apply (Bélanger, 1989; Owen, 1992). While these circumstances are not of universal concern, they are troubling to those who feel that small universities have a role to play beyond undergraduate teaching. As Owen (1992) argued, teaching and research are linked and therefore "the debate should not focus on whether faculty at small universities should participate in research, but on how to maintain and build up the research enterprise at small universities (p. 3)". 
Views of university administrators have been prominent in discussions of the factors responsible for the research disadvantage at small universities and what should be done about them. Perkin (1985) focused on the need for funds for "teaching-oriented" research and on the need for research teams. Owen (1992), building on Ingalls (1982), had research administrators at 25 small Canadian universities rank order seven possible constraints on research activity. In his respondents' view, the strongest to weakest constraints were heavy teaching loads, inadequate research facilities, few graduate students, little internal funding, lack of a research tradition, inadequate secretarial support, and limited contact with others in the field. Bélanger (1989) had noted many of these constraints, along with the "stigma of the small university". His assessment of the situation in which faculty members at small universities find themselves was frank:

Right from the start the small universities find themselves with two strikes against them, as a result of their historical context, their emphasis on the student-teacher relationship, their isolation from the large population centres, and the simple fact that they are small in size. (p. 19)

Researchers' views of problems have been less frequently cited, though Adair and Davidson (1983) did sample their opinions. In a survey of social sciences and humanities faculty at both small and large universities, they had respondents rank order the top five of 13 (plus "other") possible impediments to research activity. From amongst these choices, the top four impediments picked by small university faculty were teaching load, administrative responsibilities, insufficient funds, and being too critical of one's own work - a list similar to that of their larger university colleagues. Adair and Davidson concluded that lack of time was perceived to be the single greatest obstacle to research activity.

In the research presented here, we wished to take a more detailed look at small university faculty's views of the factors influencing research. Their perceptions could form an important part of any strategy for improving research conditions. We were interested not only in views of what constrained research but also in factors seen to facilitate it; too often only the negative alternative has been offered. Our comprehensive 
survey examined institutional, personal, and motivational factors. As faculty members cum research administrators, we took an especial interest in researchers' views of our offices.

\section{The Questionnaire}

All faculty members eligible for SSHRC funding at two small Canadian universities (Mount Saint Vincent University in Halifax, Nova Scotia and Trent University in Peterborough, Ontario) were sent a questionnaire. At Mount Saint Vincent University (MSVU) the questionnaires were sent out in mid May 1994, and accepted until the end of July; at Trent, they were sent out in mid June and accepted until the end of August. The questionnaires asked about the highest degree obtained and the amount of time at the university, research activities and preferences, views of oneself as a researcher, and views about factors which were felt to either constrain or facilitate research activities. ${ }^{1}$ The questions asked focused on issues previously seen as important influences on research (see especially Ingalls, 1982, and Harris \& Kaine, 1994). Respondents were not anonymous but were guaranteed confidentiality. Once a questionnaire was returned, information about the respondent's status as an external grant holder over the past three years, whether or not the respondent held an internal grant over the past three years, the sex of the respondent, and whether or not he or she was from a humanities, social sciences, or professional department was added to the responses.

We had intended to consider MSVU and Trent separately, as two case studies of faculty views. This seemed all the more desirable because many of the MSVU responses came from members of professional departments (Business Administration, Child and Youth Studies, Gerontology, Human Ecology, Office Administration, Public Relations, Tourism) and Trent has no such disciplines. The responses from MSVU and Trent, however, were so similar that it was pointless to discuss all aspects of each separately. Consequently, in what follows, the majority of analyses have combined data. Where it was appropriate, analyses within university were considered. We will first of all report on demographic characteristics and consider overall responses. 


\section{Characteristics of the faculty members who responded}

At MSVU, 120 questionnaires were sent to SSHRC-eligible faculty members, of which $67(55.8 \%)$ were returned completed. Sixteen of 18 (88.9\%) grant holders responded, as did 15 of $19(78.9 \%)$ unsuccessful applicants and 36 of 93 (38.7\%) non-applicants. At Trent, 161 questionnaires were sent out, with $72(44.7 \%)$ completed. Twenty-two of 31 $(71.0 \%)$ grant holders responded, as did seven of 19 (36.8\%) unsuccessful applicants and 43 of $111(38.7 \%)$ non-applicants. The overall response rate of $49.5 \%$ is within acceptable standards for survey research, and was satisfying given that the survey was conducted during the summer, after exams had ended and graduation ceremonies taken place. Response statistics make no allowance for those who did not respond because they were on sabbatical or off campus throughout the data collection period.

Response rates were particularly high for grant holders at both universities and unsuccessful applicants at MSVU. The sample is therefore selective of those disposed toward research. The non-applicant sample may also be a relatively selective one, with those who chose to respond being among those more interested in research since they troubled to fill out the questionnaire.

There were demographic differences between our faculty samples from MSVU and Trent. We have already noted that many of the Mount respondents were from professional disciplines: 20 were from the humanities, 16 from the social sciences, and 31 from professional departments. From Trent, 35 were from the humanities and 37 from the social sciences. There were also sex differences across the universities, with 38 of 67 of Mount respondents being women, but only 21 of 72 from Trent. A greater proportion of Trent faculty had a Ph.D. (.90 vs .81), had their highest degree longer (16.33 vs. 11.61 years), and had been at the university longer (16.79 vs. 12.57 years). Many of these demographic differences disappeared when Mount faculty members from professional departments were excluded. No differences in time since highest degree (new MSVU $\underline{M}=14.56$ ) and time at university (MSVU $\underline{M}=16.25$ ) were found between the humanities and social science faculties nor in proportion with Ph.D. (MSVU = .94), though sex differences remained (18 of 36 
were women at MSVU). The core of Mount Saint Vincent University's mission statement is its concern primarily with the education of women, a commitment surely related to the higher representation of women on its faculty.

\section{Faculty views}

Beyond demographic questions, we asked how the respondent would choose to spend working time on teaching, research, and other responsibilities, and what the respondent thought the university administration expected in those same three categories. Table 1 lists mean responses for each university. Overall, research $(45.00 \%)$ and teaching $(42.48 \%)$ were chosen the same percentage of time, with departmental, committee and other duties lagging far behind (12.67\%). The university was seen to want time spent on teaching $(52.24 \%)$ as opposed to research $(30.00 \%)$ or other duties $(24.56 \%)$. These percentages differed very little between universities. A MANOVA showed no significant effect of university (multivariate $\underline{F}=1.62, \underline{p}=.15$ ). On univariate comparisons, MSVU faculty had a significantly higher estimate of the university's desire for other work $(\underline{E}=4.56, \underline{p}=.035)$, though this too disappeared when only humanities and social science faculty members were considered.

Two comments on these percentages seem in order. First, the frequently expressed view (see, e.g., Smith, 1991) that faculty members are interested in research to the exclusion of teaching is clearly not applicable in either of the small universities that we studied, even though our samples were biased toward research oriented faculty members. Given that teaching interest is strong at these two small universities, which in calculations based on statistics reported at the Research at Small Universities Conference held in Charlottetown (SSHRC, 1994), had the highest (Trent) and second highest (MSVU) percentage of eligible faculty members holding SSHRC grants, then it seems reasonable to suppose it is true for small universities throughout Canada. We do not know how larger university faculties would have responded.

Secondly, faculty's view of what the university wanted with respect to teaching, research, and service $(52 \%, 30 \%, \& 25 \%$, respectively) can be compared to what Bélanger's (1989) sample of Vice Presidents 
Table 1

Mean faculty responses to questionnaire items by university

\begin{tabular}{ccc}
\hline Mount Saint & & \\
Vincent & Trent & Overall \\
\hline
\end{tabular}

Choose research time

$\begin{array}{lll}44.58 & 45.39 & 45.00\end{array}$

Choose teaching time

42.72

42.26

42.48

Choose dept, comm., other university time

12.73

12.61

12.67

Administration wants research time

28.20

31.68

30.00

Administration wants teaching time

53.19

51.37

52.24

Admin. wants dept, comm., other university time

27.40

21.92

24.56

Influences on Research

The time you spend on non-teaching commitments*

The time you spend on teaching commitments

1.55

1.84

1.70

The availability of graduate students*

1.93

2.00

1.96

Availability of library holdings

1.96

2.42

2.20

Your family responsibilities

2.33

2.34

2.33

The availability of secretarial support

2.37

2.58

2.48

The availability of research assistance

2.37

2.65

2.52

The availability of researchers with similar interests

The availability of research space*

2.47

2.63

2.55

2.54

2.69

2.62

The availability of research equipment*

2.36

2.93

2.65

The availability of computer user services

2.54

2.77

2.66

The availability of computer hardware*

2.55

2.87

2.72

The research incentives provided by the university

The university research culture*

2.69

3.06

2.88

2.76

3.14

2.96

The research orientation in your department*

2.79

3.20

3.00

The availability of congenial colleagues

2.80

3.31

3.06

Your knowledge of important techniques

2.98

3.21

3.10

Your personal health

3.12

3.16

3.14

Your ability to get an external grant

3.15

3.20

3.18

Your ability to have completed research published 3.73

3.20

3.20

Your ability to get internal grant funds

3.79

3.66

3.69

Your ability to find topics to do research on

3.98

3.65

3.72

Your freedom to design your own research program

4.04

Your motivation to carry out research

4.11

4.10

4.04

4.28

4.17

4.41

4.26

$\overline{\text { *means differed across universities, } \mathrm{p}}<.05$ 
(Academic) at small universities said they expected $(54 \%, 26 \%$, and $20 \%$, respectively). It seems faculty members have a reasonable idea of university expectations, though there are indications that they feel overworked. When responses to the three questions regarding university wants are totalled, they show that faculty felt meeting university expectations would require $106.8 \%$ of working hours.

All remaining questions were answered on a 1-5 Likert scale, and were of three types: a) those asking about the influence of factors on the quality and/or quantity of research, (b) those asking researchers to rate themselves, and c) those asking about the influence of the research office on various aspects of research. ${ }^{2}$

Influences on research. On the influence questions, 1 was defined as a negative influence, 3 as no influence, and 5 as a positive influence. If responses averaging less than 2.5 are considered to identify a negative factor, 2.5-3.5 as not influential, and over 3.5 as a positive factor, then 5 of 24 factors were negative ones (see Table 1). From the greater to lesser (i.e., from lowest to highest mean), these negative influences were time spent on non-teaching commitments, time spent on teaching commitments, the availability of graduate students, availability of library holdings, and family responsibilities. This list of constraints was remarkably constant across universities, with both faculties having the same four factors as the greatest impediments. Indeed, the only difference of note in the top ten constraints at each university was that space was a relatively more important constraint at MSVU (fifth) than Trent (eleventh).

Though not directly comparable with the list which Owen (1992) had research administrators generate, our findings highlight some different faculty concerns. The primary constraint was seen as non-teaching commitments, a factor not previously identified. We believe that "non-teaching commitments" refer to university service, and informal conversations with respondents suggest that is how it was interpreted (though, given the importance this factor assumed, this needs further exploration with less ambiguous wording). Owen (1992) had both internal funding and university research culture listed among constraints, though neither was viewed as detrimental by our respondents. Indeed, ability to get internal funds was viewed as a positive influence, while research culture was not seen as 
an influence at all (though see later for university differences on culture). One of the advantages of our methodology was that, beyond rank ordering factors, it allowed assessment of perceived magnitudes, showing these two "constraints" were not perceived as obstacles at all.

Faculty viewed five factors as positive influences $(\underline{M}>3.5)$ on research, the strongest being the motivation to carry out research, followed by freedom to design one's own research program, the ability to find research topics, one's ability to get internal funds, and one's ability to get research published. The same five factors, in almost identical order, were identified at each institution. The high level of research motivation is reassuring, suggesting that faculty members are ready to take advantage of whatever strategies might be implemented to facilitate research.

While the similarities in responses by faculty of the two institutions were impressive, there were also differences. These were not obvious in the relative assessment of influences, though as we have seen space was a relatively greater concern at MSVU, but in the assessed magnitude of influences. A MANOVA comparing mean ratings on all 24 influence items across universities showed significant differences (multivariate $\underline{F}=1.98, \underline{p}=.009$ ). Univariate $F$ tests showed differences on constraining variables, with MSVU respondents seeing greater impediments. MSVU means for the influences of nonteaching commitments, university research culture, and research orientation in one's department, as well as the availability of graduate students, space, equipment, and computer hardware were all lower than those at Trent. The greatest disparity was in the mean for space (2.36 at MSVU; 2.93 at Trent). Most of these differences remained even when professional faculty members at MSVU were not considered. Lest it be thought that faculty at the Mount were just more cranky than at Trent, we found those in the humanities and social sciences at MSVU rated ability to get internal funds as a more positive influence on their research than their Trent counterparts. No other differences on positive influences occurred in either analysis.

The differences in faculty perceptions across universities are probably a reflection of the differing circumstances at the two campuses. For example, at MSVU, research space (and office space, for that matter) has been at a premium, and essentially no faculty member in SSHRC eligible 
disciplines has individual dedicated research space. Some departments, e.g., the ten member sociology department, have no space at all outside of their own offices. Trent has not experienced the same widespread shortage. University differences in faculty's perceptions of the availability of graduate students are likewise easily accounted for. At MSVU the only graduate programs are in Education and Human Ecology. At Trent, most faculty members would have access to graduate level activity. Trent has one single- discipline graduate program (Anthropology), and also three inter- disciplinary M.A. programs which span the social sciences and/ or humanities. These programs provide an opportunity for most faculty members to be involved in graduate studies as thesis supervisors, members of supervisory committees or as instructors in graduate level courses if they choose. This involvement has been a stimulus to research in many cases.

We have detailed the circumstances underlying these two differences because we feel they help establish the validity of faculty perceptions and our questionnaire. The remaining points of difference between the universities are either less easily translated into observable factors (nonteaching commitments, university culture, departmental research orientation) or require data less readily available (on equipment and computer resources). We think our respondents' perceptions of these also reflect real differences across universities, though we will not share our speculations. We would suggest, however, that it is not coincidental that Trent faculty had overall more positive perceptions of influences, a more positive perception of research culture, and a higher percentage of eligible faculty with research grants.

Self ratings. Overall, respondents rated themselves highly on the personal motivational factors we asked about. Again considering mean responses above 3.5 as high, then respondents rated themselves as high on (ordered from highest to lowest) commitment to research, competence and ambitiousness as researchers, and in interest in getting money for research (see Table 2). As a group, they did not rate themselves as low on any of the ten things asked about. Universities did not differ in the ordering of these ratings, nor were there any differences in the means (a MANOVA comparing universities on the 10 self rating items showed 
Table 2

\section{Mean Faculty Responses to Questionnaire Items by University}

Mount Saint

Vincent Trent Overall

Self-ratings

Competitiveness as a researcher

Preference for short term over long term projects

Preference for research as opposed to teaching

Productivity as a researcher

Satisfaction with research achievements

Interest in getting money to support research

Ambitiousness as a researcher

Competence as a researcher

Commitment to research

Research Office

Influence on your research focus

Influence on your research productivity

Influence on external application decision

no overall effect $[\underline{F}=0.87, \underline{p}=.567]$ nor any significant univariate $F s$ ). Faculty at both universities had an equally positive view of their research potential and ambitions. It is still clear, however, that commitment and ambition in research were not to the exclusion of teaching: the average rating for "preference for research as opposed to teaching" was 3.06. Of 139 responses to this question, 42 were above the middle response option and 36 were below it. This overall lack of preference is corroborating evidence for the percentages reported earlier on how faculty members would like to divide their working time. The archetypical faculty member who wants to do research and not teach is no more frequently found in small universities than those keen to devote themselves to teaching. 
The research office. Faculty at both universities reported favourable influences from their research offices (see Table 2). Means of greater than 3.5 were found for their influence on decisions about applying for an internal grant and for an external grant, as well as their influence on research motivation. The remaining factors, influence on research focus or research productivity, were in the upper reaches of the no influence range. Assessments of research office influence did not differ across universities (multivariate $\underline{\mathrm{F}}=1.54, \mathrm{p}=.183$, and no univariate $\mathrm{Fs}$ were significant).

The high regard accorded the research office at both institutions should be heartening news for those who view such an office as an integral part of any administrative strategy to promote research (Bélanger, 1989; Ingalls, 1982). At MSVU, there has been a full time Director of Research for the past three years, though the office has been in existence since the early 1980s (see Ingalls, 1982). The Director of Research, who is assisted by a three-quarters time office administrator, is charged with maintaining and disseminating sources of funds for faculty members, encouraging and approving grant applications, and developing university policies for research, among other things. Incidentally, it may be worth noting that since a full time Director was appointed, the number of SSHRC grants held at MSVU rose dramatically (there was no change in the number of NSERC grant holders). At Trent the Associate Dean of Research and Graduate Studies has similar responsibilities to those of the Director of Research at MSVU in terms of institutional support for faculty research, and is also responsible for coordinating graduate studies activities. A full time position of University Research Officer was established eight years ago, and since that time the number of faculty holding SSHRC research grants at Trent has increased from 6 to 23. The number of NSERC grants has increased less dramatically, but the total value of NSERC grants and scholarships has grown by the second highest proportion in Canada. University investment in this area has certainly paid off.

\section{General Discussion}

Our major purpose in undertaking this study was to highlight faculty views of factors which influence research in the small university. In so doing, we hoped to inform strategies for facilitating research in our own 
and other small institutions. It was not our intention to identify factors which necessarily account for differences in funding across large and small universities. As Owen (1992) recognized, opinions about perceived constraints in small universities cannot be used in simple fashion to explain institutional differences. After all, personnel in small and large universities might identify the same factors, as Adair and Davidson (1983) found when surveying humanists and social scientists at both types of institutions. Overall, faculty views of obstacles to their research were similar, with teaching load identified as far and away the greatest impediment in either context. On the other hand, the similarity of responses across large and small universities does not eliminate a factor from potentially explaining the differences either, particularly when only rank ordering and not magnitude of any given constraint is measured. As Bélanger (1989) documented in a direct comparison of large and small universities, differences in teaching loads do exist, along with differences in graduate student/ professor ratios, and research resources. These may therefore account for institutional differences, whatever similarities in faculty opinions across institutions exist. We cannot agree with Owen (1992) that similarities in viewpoints on teaching made it "probable that other factors in the institution's culture or infrastructure may place additional barriers in the path of researchers at smaller institutions (p. 5)", reasoning which led him to focus on research climate and not the teaching constraint which was recognized as primary by his respondents. The safest conclusion to be drawn is that views of research constraints allow no conclusions about the source of differences, but may be useful in informing the debate on how to strengthen research in small universities.

If we accept the faculty's view that the factors most constraining to research are time spent on nonteaching and teaching commitments, what is to be done? From one point of view, nothing. Teaching, research, and service are all part of a faculty member's responsibilities, and therefore it should not be surprising that they place competing (though sometimes overlapping) demands on time. On the other hand, perhaps it is time to rethink the degree to which universities require all faculty members to do all things. Institutions other than universities have seen merit in increasing job specificity as a response to a rapidly expanding knowledge base 
and increased need for more and more specialized knowledge, as Keller (1983) and Gross (1963) have pointed out. Researchers in a position to compete for external research funds are handicapped by being "in the awkward position of having to perform increasingly as versatile generalists for their institutions while receiving their status and financial rewards increasingly for specialized research, publications, and national attention as independent professionals" (Keller, p. 24). The university's status suffers with that of its scholars. This quotation from Keller, however, reflects the very premises which cause most faculty members to fear supporting policies that would formally acknowledge divisions of labour amongst faculty members on teaching, research, and service; that research is most highly valued, and those not specializing in it would become second class citizens within the university context and their profession.

We have no satisfactory answer to this objection, though would note O'Neill's (1993) cogent argument that the notion that research and not teaching is rewarded by universities is a myth. In practice, universities do reward teaching, as those who have had experience with the tenure or promotion committees at either of our small universities could attest. While we would not like to see any faculty member become relieved of teaching, research, or service duties entirely, we would like to see a system which formally acknowledged specialization. With the assurance of formal recognition for their efforts, it seems likely that those expressing a preference for teaching ( $25.9 \%$ of our sample) would happily concentrate more effort there, allowing others with a preference for research more time to focus on it. Strengthened research productivity and research grant numbers within the small university might well be the result. Informal arrangements already exist at some small universities. We have been told, for example, that at some institutions faculty members are assuming extra teaching duties to allow departmental colleagues to allocate more time to research projects. While applauding co-operative efforts, we would prefer a university wide policy which would ensure that all receive appropriate recognition for their efforts. We would not favour a system whereby positions would be designated as research or teaching oriented, but rather would give faculty members the option of specializing to the extent that circumstances allowed. 
As an aside, it is worth noting an incidental though important advantage which might be realized if specialization were allowed. Using person-environment fit theory, Blackburn and Bentley (1993) measured stress in faculty members as the degree to which there was a mismatch between the percentage of time they wanted to give to research and what they felt the institution wanted from them. They found that personal, not environmental, variables were the most effective mediators of a correlation between stress and productivity. They suggested:

... if an institution wants to increase research output but not raise faculty stress to a dysfunctional level, it needs to examine the possibilities and costs of interventions. Environmental variables are more easily changed than are personal attributes, but, as seen, the ones used here are not effective. A supportive climate has not removed the strains faculty express as a consequence of not allocating their research effort in either their personal preferred way or in their perceptions of what the institutions desires. (p. 742)

A flexible system of specialization such as we have suggested could both increase overall research productivity and reduce stress.

Such a controversial strategy will surely not be implemented quickly. More immediate means of redressing the balance of university responsibilities are available. It is clear from the survey results that faculty members view the time spent on non-teaching commitments as a major impediment to research and consider that demands of this type are excessive. Both universities have undertaken reviews of committees with a view to decreasing their number and size, Trent more recently than MSVU. Though we are not unaware of the irony of proposing a "committee on committees", we suggest that all universities could profit from looking at this area with the view to freeing up faculty time for research and teaching.

Our data point out other ways in which research might be facilitated. While the abstract concept of research culture was not a significant influence on research in faculty members' minds, we should not be quick to dismiss its importance. As we have noted, the two faculties differed in their perception of culture, with the faculty having the more positive view 
holding proportionally more research grants. Owen (1992) suggested specific ways of improving research culture, and considered many of the factors that were seen as important by our respondents. In some sense, our list of constraints as faculty perceived them can be seen as prioritizing among the factors which he identified and on which the university needs to be seen to take action to improve research culture. Of the things that could be more readily acted upon (graduate programs, e.g., are not easily generated), our faculty would have library resources and secretarial support improved. Space was a major issue at Mount Saint Vincent University. Universities might consider ways to ensure that their policies alleviate family responsibilities as much as is possible for an employer to do.

Finally, we would emphasize again the positive influence respondents assigned to their research offices. This confirms the value that Bélanger, Ingalls, Owen and others have put on the existence of such an office. We think that research officers might profit by actively using the sort of survey we have just discussed, not just to set general priorities but also to target efforts on specific researchers. Ultimately, knowledge of the specific characteristics of faculty members which make them more prone to do research and apply for and receive external grants may be most useful. We are currently preparing a report which will look at what differentiates grant holders, unsuccessful applicants, and non-applicants, and how we can predict who will apply.

\section{References}

Adair, J. \& Davidson, R. (1983). Research activity in the social sciences: A review of funding, productivity and attitudes of university-based social scientists. Ottawa: Social Science and Humanities Research Council of Canada.

Bélanger, C. (1989). University entrepreneurship and competition: The case of small universities. The Canadian Journal of Higher Education, 19, 13-22.

Blackburn, R. \& Bentley, R. (1993) Faculty research productivity: Some moderators of associated stressors. Research in Higher Education, 34, 725-745.

Gross, N. (1963). Organizational lag in American universities. Harvard Educational Review, 33, 58-73. 
Harris, G. \& Kaine, G. (1994). The determinants of research performance: A study of Australian university economists. Higher Education, 27, 191-201.

Ingalls, W. (1982). Increasing research productivity in small universities: A case study. The Canadian Journal of Higher Education, 12, 59-64.

Keller, G. (1983). Academic Strategy: The management revolution in American Higher Education. London: The Johns Hopkins University Press.

O'Neill, G.P. (1993). Myths revisited. The Canadian Journal of Higher Education, 13, 108-113.

Owen, M. (1992). Research at small Canadian universities. The Canadian Journal of Higher Education, 22, 1-14.

Perkin, J. (1985). Research in small universities. The Canadian Journal of Higher Education, 15, 1-4.

Smith, S. (1991). Report of the Commission of Inquiry on Canadian University Education. Ottawa: AUCC.

Social Sciences and Humanities Research Council. (1994). Preliminary Program Statistics 1994-1995. Report prepared for the Small Universities Research Conference, UPEI, Charlottetown.

\section{Notes}

1 A copy of the questionnaire is available from the authors.

2 The sections that follow report on average responses. Measures of variability have been omitted to make the presentation more readable. Responses ranged from 1 to 5 on all items, with the following exceptions: no-one rated time spent on teaching commitments or the availability of research equipment as a strong positive influence (5), and no-one rated her or his ability to find topics to do research on, or the influence of the research office on either research motivation or focus as a strong negative influence (1). A full listing of standard deviations is available from the authors. 